\title{
Online Social Media Applications for Constructivism and Observational Learning
}

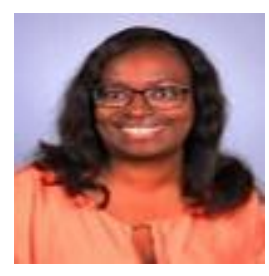

Lydia Mbati

University of South Africa

\section{Abstract}

Web 2.0 technologies have a range of possibilities for fostering constructivist learning and observational learning. This is due to the available applications which allow for synchronous and asynchronous interaction and the sharing of knowledge between users. Web 2.0 tools include online social media applications which have potential pedagogical benefits. Despite these potential benefits, there is inadequate utilization of online social media applications in learning management systems for pedagogical purposes. Reasons cited for the limited uptake of online social media applications in learning management systems include the lack of consideration regarding the pedagogical benefits of these applications (Christie \& Garrote-J urado, 2009, pp. 273-279). There is limited information regarding experiences of the use of online social media that foster constructivist and observational learning. Using a qualitative meta-ethnographic approach, this article explores the experiences of students and instructors regarding online social media applications for constructivism and observational learning. Constructivist criteria (Baviskar, Hartle, \& Whitney, 2009, pp. 543-544) and observational learning, based on Bandura's (2001, pp. 265-299) social cognitive theory, formed the theoretical grounding for this research. The findings suggest that discussion forums are ideal for the stimulation of constructivism and observational learning in online learning programmes.

Keywords: Learning management systems; online social media; constructivism; observational learning 


\section{Introductory Background}

Online social media usage has grown exponentially over the last decade. This growth has been driven by the Web 2.0 concept, which allows for the creation and sharing of user generated content (Hershey, 2010, p. 196). Online social media includes collaborative platforms such as wikis, blogs, and discussion boards that can be used to form virtual communities. Online social media are communication and collaboration tools found in varied arenas including educational arenas.

With the introduction of Web 2.0 technology in the field of education, the possibilities for fostering constructivist and observational learning have increased. These possibilities are driven by the nature of emerging online applications (Siemens \& Tittenburger, 2009, p. 35). In order to fully exploit the available possibilities, online instructional designers and instructors ought to align instructional design and facilitation of online teaching and learning along established learning paradigms. With the large number of applications available in learning management systems (LMS), it is sound for instructional designers, instructors, and institutional information technology (IT) departments to invest in those tools and applications that foster constructivist learning and observational learning. In spite of the potential pedagogical benefits offered by online social media applications, there is a general lack of uptake of learning management systems for pedagogical use by online instructors.

In this regard, a meta-ethnographic study was conducted to explore the experiences of lecturers and students regarding online applications found in learning management systems. The aim of the study was to identify applications that foster constructivism and observational learning among students. It is against this backdrop that the research reported on in this article took place. In the following sections, an overview of institutional learning management systems and online applications is presented. This area addresses available literature regarding the use of learning management systems for pedagogical purposes. A review of literature related to media for constructivism and observational learning is presented, followed by explanations of constructivism and observational learning which served as theoretical grounding for this study. The methodology employed and findings revealed are addressed with conclusions drawn based on the findings obtained. This article concludes by presenting recommendations, based on the findings, regarding online applications that foster constructivism and observational learning. These recommendations may assist institutional IT departments and online instructors as they make choices regarding the selection, management, and use of online social media in institutional LMS. 


\section{The Use of Online Media Applications in Learning Management Systems}

LMS are internet based systems now found in higher education institutions. LMS are created for course administration as well as for pedagogical use. These widely used systems vary from one to another in terms of sophistication and adaptation. They also allow for customisation to meet various needs. However, they have certain characteristics that define them as LMS. The first is the possibility for both synchronous and asynchronous communication using the LMS. This is made possible by the applications available such as email, discussion boards, and chat platforms. Secondly, these systems allow for the development and delivery of learning resources and links to internet resources. In terms of assessment, LMS allow for the submission of assignments, feedback, and multiple choice testing. Lastly, LMS enable management of learning such as registration information, the display of time-tables, and the management of student activities (Coates, J ames, \& Baldwin, 2005, pp. 20-21). LMS are essential in both campus based institutions and open and distance learning institutions. When effectively used they have the potential to improve and support learning within both modes of education facilitation (Dalsgaard, 2006).

Despite the potential benefits to learning offered by LMS, the use of these platforms by instructors and students is limited. Literature has addressed the problem of lack of uptake of LMS for pedagogical purposes. The lack of sufficient knowledge regarding the pedagogical benefits of LMS is one factor limiting its use and adaptation (Chen, 2011, pp. 42; Christie \& Garrote-J urado, 2009, pp. 273-279). Another factor that contributes to the limited adoption of LMS for pedagogical purposes is the management and selection of LMS, which lies in institutional IT departments. In this regard, academics have limited input in the choices made by IT departments (Bell \& Shank, 2004, in Black \& Blankenship, 2010, pp. 459). Another reason for the limited adoption of LMS for pedagogical purposes is the lack of competence development and support in how to use the LMS for pedagogical purposes, on the part of instructors and students (Christie \& Garrote-J urado, 2009 pp. 277).

While the studies cited have addressed pedagogical affordances of various applications, there is a need for aligning these affordances to learning theories and typologies. It is against this backdrop that a meta-ethnographic study was conducted to explore the experiences of online students and instructors regarding online social media and learning. The purpose of carrying out the study was to explore the pedagogical benefits of online social media found in LMS. The pedagogical benefits the study sought to explore were aligned to the criteria for constructivist and observational learning. 


\section{Media for Constructivism and Observational Learning}

Research from a positivist paradigm has revealed that online media applications foster improved learning outcomes (Liang \& Tsai, 2008, pp. 226-237; Sultan, Woods, \& Koo, 2011, pp. 149-163). While research in online learning environments has added to the understanding of the role media plays in fostering learning, the media in question was not based on Web 2.0 technology (Sultan, Woods, \& Koo, 2011, pp. 149-163). Additionally, the pedagogical affordances of various online media applications are known (Clark \& Mayer, 2011 pp. 284-285; Siemens \& Tittenberger, 2009, pp. 42). Discussion forums have proven useful as reflective tools (Juwah, 2010, pp. 24-25). Similarly, the pedagogical benefits of interaction in virtual environments have been empirically established (Yang, Yeh, \& Wong, 2010, pp. 287-306). While podcasts have been proven to stimulate constructivist learning (Ngambi \& Lombe, 2012, pp. 181-192), knowledge regarding the pedagogical potential of other online media applications in institutional learning management systems is lacking leading to a lack of uptake by lecturers and students.

The use of collaboratively observed videos as a means of achieving observational learning has been established in literature (Craig, Chi, \& VanLehn, 2009, pp. 179-189). In addition, videos have also been proven as a means through which individuals with special needs can be effectively taught socially expressive behaviours (Charlop, Dennis, Carpenter, \& Greenberg, 2010, pp. 371-393; Charlop-Christy, Le, \& Freeman, 2000, pp. 537-552; Geiger, LeBlanc, Dillon, \& Bates, 2010, pp. 279-383; Nikopoulos \& Keenan, 2003, pp. 87-108; Sherer, Pierce, Paredes, Kisacky, Ingersoll. \& Schreibman, 2001, pp. 140-148) and vocational skills and life skills (Keen, Brannigan, \& Cuskelly, 2007, pp. 291-303; LeBlanc, 2010, pp. 333-337). These studies have contributed to an understanding of the role video based media plays in fostering learning amongst learners with special needs.

\section{Constructivism}

Constructivism in education is based on the works of Lev Vygotsky (1978) in Pritchard (2005, pp. 254), a Russian psychologist and Jean Piaget (1961 in Pritchard, 2005, pp. 254). The common thread that links constructivist thought is that learning occurs when the students create new knowledge based on existing knowledge which they inherently possess. Constructivism, as a learning paradigm, formed part of the theoretical and conceptual framework for the research. Baviskar, Hartle, andWhitney (2009, pp. 543544) identify four constructivist criteria and emphasize the need to adhere to the four criteria for any teaching and learning to be considered constructivist.

The first critical element is the eliciting of prior knowledge. The premise of this element is that all new knowledge is acquired in relation to prior knowledge which the student possesses (Baviskar, Hartle, \& Whitney, 2009, pp. 543). This is achieved by either the 
lecturer's use of mechanisms to elicit prior knowledge or the drawing of the student's attention to his prior knowledge. This criterion is referred to as elaboration (Loyens, Rikers, \& Schmidt, 2007, pp. 582) who state that elaboration leads to significant learning gains. The creation of cognitive dissonance is the second criterion for the stimulation of constructivist learning, according to Baviskar, Hartle, andWhitney (2009, pp. 544). In this second criterion, the student is made aware of the difference between his prior knowledge and new knowledge. The third criterion for constructivist learning is the application of the knowledge with feedback. At this stage the student is required to interpret and modify prior knowledge in the context of new knowledge. This particular criterion is consistent with the defining characteristic of constructivism as a social and collaborative activity as noted by Al-Fadhli and Khalfan (2009, pp. 531) and others such as Loyens et al. (2007, pp. 582). This serves as a means to integrate the new knowledge permanently (Baviskar, Hartle, \& Whitney, 2009, pp. 544). Reflection on learning is the fourth criterion for constructivist learning. On integrating the new knowledge permanently, the student ought to become aware that learning has taken place (Windschitl, 2002; Yager, 1991 in Baviskar, Hartle, \& Whitney, 2009, pp. 544).

\section{Observational Learning}

Observational learning based on Bandura's (2001, pp. 265-299) social cognitive theory was further grounding for the research. Bandura (2001, pp. 266) explains that human nature is a vast potentiality that can be fashioned from direct and observational experience. In observational learning, a single model can transmit new ways of thinking and behaving simultaneously to countless people in dispersed locales. Social cognitive theory also posits that humans operate within socio-structural networks which they are products of and producers of. As a result human nature is shaped by direct observable experience through various processes which are intrinsically human, symbolizing capabilities, self-regulatory capabilities, self-reflective capabilities, and vicarious capabilities.

As asserted by social cognitive theorists, human beings have evolved an advanced capacity for observational learning that enables them to advance their knowledge and skills beyond their fields of experience. Human beings similarly have the unique ability to use information conveyed by the rich variety of models for all behavioural, cognitive, and affective learning. This is achieved through both direct experience and vicariously by observing people's actions and its consequences for them (Bandura, 1986; Rosenthal \& Zimmermann, 1978 in Bandura, 2001, pp. 271). Much social learning occurs from modelling based on one's direct realm of existence; however, a vast amount of social learning is gained from modelling in the symbolic environment of mass media (Bandura, 2001, pp. 271).

Stefanone, Lackaff, andRosen (2010, pp. 512) explain that modelling refers to the process through which individuals observe others, interpret the behaviour, and adjust 
their own in response. The development of television is viewed by Bandura (1986 in Stefanone, Lackaff, \& Rosen,2010, pp. 512) as an especially important source of behaviour models, enabling people to "transcend the bonds of their immediate social life" (Bandura, 1986, pp. 55). In comparison to the quantity of information about the world available in daily life, the amount of environment rich information provided via media is vast. To the extent to which one's images of reality, mediated and vicarious, rather than directly experiential and experimental, is greater is a result of the impact of media (Bandura, 1986). Whereas previously modelling influences were largely confined to the behaviour patterns exhibited in one's immediate environment, the accelerated growth of video delivery technologies has vastly expanded the range of models to which members of society are exposed. Because the symbolic environment occupies a major part of people's everyday lives, much of the social construction of reality and shaping of public consciousness occurs through electronic acculturation (Bandura, 2001, pp. 271). Modelling has proven to yield better results in the area of training (Yi \& Davis, 2003, pp. 147). Modelling is thus a more complex process than mimicry or imitation, and Bandura (2001, pp. 273) identifies four specific functions of the process.

\section{Attentional Processes}

Attentional processes during modelling for observational learning determine what is selectively observed in the profusion of modelling influences and what information is extracted from ongoing modelling events. This is achieved by the person exercising attentiveness when observing modelling. According to Bandura (2001, pp. 272) a number of factors influence what is modelled. He classifies these factors as the observer factors, which include cognitive skills, preconceptions, and value preferences. Similarly, the factors may be classified as the modelled activity factors: salience, attractiveness, and functional value. Separate factors include the structural arrangements of human interactions and association networks, which largely determine the types of models to which people have ready access (Bandura, 2001, pp. 272).

\section{Retention}

Bandura (2001, pp. 272) identifies the second major sub-function of modelling for observational learning as retention. Retention involves the active process of transforming and restructuring information conveyed by modelled events into rules and conceptions for memory representation. Retention is greatly aided by symbolic representations of modelled information into memory codes and cognitive rehearsal of the coded information (Bandura 2001, pp. 272). Actions thus must be cognitively registered as symbolic representations in one's memory in order to regulate behaviour (Yi \& Davis, 2003, pp. 147). Bandura (2001, pp. 272) emphasizes that preconceptions and affective states exert biasing influences on these representational activities. He further asserts that recall involves a process of reconstruction rather than simply retrieval of registered events. 


\section{Production Processes}

The third sub-function of modelling for observational learning is the behavioural process. Bandura (2001, pp. 272) explains that this process involves the translation of symbolic conceptions into appropriate courses of action. This is achieved through a conception-matching process in which conceptions guide the construction and execution of behaviour patterns that are then compared against the conceptual model of adequateness. The behaviour is modified on the basis of the comparative information to achieve close correspondence between conception and action. The mechanism for translating cognition into action involves both transformational and generative operations. Execution of a skill must be constantly varied to suit changing circumstances. Adaptive performance, therefore, requires a generative conception rather than one to one mapping between cognitive representation and action. By applying an abstract specification of the activity, people can produce many variations on the skill (Bandura 2001, pp. 272). Yi and Davis (2003, pp. 147) elaborate that the retained symbolic memory of actions must be reconverted into overt actions to generate desired responses.

\section{Motivational Processes}

The fourth sub-function in modelling for observational learning as identified by Bandura (2001, pp. 274) is the motivational process. Social cognitive theory distinguishes between acquisition and performance because people do not always perform everything that they learn. Bandura (2001, pp. 274) identifies the three major types of incentive motivators which influence performance as direct, vicarious, and self-produced. People are more likely to exhibit modelled behaviour if it results in valued outcomes rather than in punishment or unrewarding outcomes. People are motivated by the successes of others who are similar to themselves. Personal standards of conduct provide a further source of incentive motivation. The self-approving and self-censoring reaction people generate on their own behaviour regulate which observationally learned activities they are most likely to pursue. They pursue activities that they find satisfying and that give them a sense of worth but reject those they personally disapprove of (Bandura, 2001, pp. 274). The symbolic memory of actions weakens unless perceived consequences of performing the actions are favourable to cause repeated performance (Yi \& Davis, 2003, pp. 147)

\section{Methodology}

This research is based on a meta-ethnographic approach. Meta-ethnography is a qualitative method that is used to synthesize understanding from ethnographic accounts. It allows interpretivists to derive understanding from multiple cases, accounts, narratives, or studies. Meta-ethnography is described as the synthesis of interpretive research (Noblit \& Hare, 1988, pp. 10-12), The procedures that were therefore followed 
when conducting the meta-ethnography used the guidelines as prescribed by Noblit and Hare (1988, pp. 26-29).

The initial step of the meta-ethnographical method entailed the identification of the interest of the research (Noblit \& Hare, 1988, pp. 26-29). In this case the interest of the research was the exploration of online social media applications that lead to constructivist learning and observational learning in online learning environments. The objective of this research was to synthesize previous research theses produced internationally, in order to gain understanding into the experiences of lecturers and students regarding online social media applications, constructivism, and observational learning. This part of the meta-ethnographic approach involved the conducting of a library search in order to access the data. The keywords of constructivism, observational learning, and online media were used to conduct the search. The search yielded 346 theses and dissertations.

The relevant theses and dissertations were identified using four guidelines. The first was what was credible and of interest to the focus of the research. Inclusion and exclusion criteria were drawn in order to allow for sifting through the total number of research reports and extricating what was relevant to the research objective. In this case, the first criterion for selecting sources for the meta-ethnography was the inclusion of only completed primary research in the form of a research dissertation or research thesis in English. The selected sources addressed the experiences of students regarding online media and learning. The second criterion was the inclusion of theses and dissertations based on research conducted between 2001 and 2011. Data based on research prior to 2001 and after 2011 were not included. The third inclusion criterion was theses and dissertations that were fully accessible. At this stage the theses and dissertations that could not be fully accessed were excluded from the study. The abstracts of the remaining articles were read to determine which of the research designs departed from a qualitative research approach which constituted the fourth inclusion criterion. The remaining four articles which are based on qualitative designs appear in Table 1. The selected articles were subjected to the subsequent meta-ethnographic procedures as indicated by Noblit and Hare (1988, pp. 28-29).

Table 1

Theses and Dissertations Focusing on Online Media Applications and Learning

\begin{tabular}{|l|l|c|}
\hline Title of the research & Author & Year \\
\hline $\begin{array}{l}\text { Elementary lecturers' perceptions of } \\
\text { technology as a catalyst for constructivist } \\
\text { practices in the classroom: a case study }\end{array}$ & $\begin{array}{l}\text { Lynne Brown } \\
\text { Menard }\end{array}$ & 2010 \\
\hline $\begin{array}{l}\text { Social implications facing online } \\
\text { students: a case study of undergraduate } \\
\text { multimedia students }\end{array}$ & Mia Boster & 2009 \\
\hline $\begin{array}{l}\text { The lived experiences of university } \\
\text { faculty who teach using a hybrid } \\
\text { instructional model }\end{array}$ & $\begin{array}{l}\text { Udeme Taylor } \\
\text { Ndon }\end{array}$ & 2006 \\
\hline
\end{tabular}


Instructional uses of computer-mediated text-based messaging tools: a case of faculty and student experiences and perceptions
2002

The available qualitative theses were read through in order to note the interpretive themes in each thesis. The reading of each thesis was conducted more than once and the themes as they relate to the focus of the study were noted. For this purpose Atlas.ti qualitative data analysis software was utilized.

Noblit and Hare (1988, pp. 62) indicate that lines-of-argument synthesis allows for inferences to be made about the whole based on selective studies of the parts, and is amenable to the meta-ethnographic approach. In line with a lines-of-argument synthesis, similarities and differences amongst the studies to be synthesized were discovered and constructed in a holistic synthesizing scheme.

\section{Findings}

In this section links were made between the findings and the criteria of the theoretical framework for the research. The findings as they relate to constructivism followed by the findings in relation to observational learning are presented.

\section{Research Findings in Relation to Constructivism}

As is consistent with the first criterion for constructivism (Baviskar, Hartle, \& Whitney, 2009, pp. 543), the students have to be able to elicit their prior knowledge regarding learning content and link this prior knowledge with new knowledge. In the case of this research, the experiences of students using technology were explored and linked to the various criteria for constructivism. The link between the student experiences and the constructivist criterion of eliciting prior knowledge emerged in the use of discussion boards for online teaching and learning. Some quotations associated with this particular criterion are as follows:

The Discussion Board could help us to develop our own thoughts. A student has to have (his or her) ducks in a row before posting. The Discussion Board forces students to support their thinking, and if they can't, they should keep their mouths shut. (DeArment, 2002, p. 105)

I can think of several times on the Discussion Board where I have read articles (assigned for class), and 
someone else has read the same article, and (his or her) comments kind of articulated something that resonated with my response, an idea that I hadn't really fully formed yet. It helped me to kind of put it together. (DeArment, 2002, pp. 104)

This teacher recognized how her students were independently pulling from their life experiences and connecting them to the district strategic objectives. (Menard, 2010, pp. 95)

The second criterion for constructivist learning was that of achievement of cognitive dissonance. As was the case with the first criterion, the experiences of students using technology were explored and linked to cognitive dissonance and the media that stimulated cognitive dissonance. The medium that stimulated cognitive dissonance was the discussion board, as shown in the following quotation:

Scrutinizing a message she had posted for Unit 4, Meg recalled,

I had browsed sites as part of my work, and (my thoughts) sort of clicked when I read the discussion; that's when I posted. I think I got something out of trying to gather my thoughts together. (DeArment, 2002, pp. 142)

The criterion of application of knowledge was absent from the data with no themes emerging that inferred the application of knowledge with feedback.

The final criterion for constructivist learning was that of reflection. This criterion was inferred from the data and the media that encouraged reflection were those that allowed for text messaging and included blogs and discussion boards. Examples of the quotations are as follows:

Another example of how the participants encouraged active and independent learning was through selfreflection. Madison indicated that he used the critical incident questionnaires which appear in the Brookfield book "How to be a Critical Reflective Teacher" to ask students to "report on their experiences each week on what they learned, and what frustrated them. (Livonia) (Ndon, 2006, pp. 115)

...online text-messaging tools provided varied ways they could access and engage with course information. She pointed out to the researcher examples of Discussion 
Board exchanges in which students reflected on awareness of their own learning. (DeArment, 2002, pp.

84)

\section{Research Findings in Relation to the Functions of Observational Learning}

In this section the findings were linked to the criteria for observational learning which, in addition to constructivism, formed the theoretical framework for the research.

\section{Attentional processes.}

With regard to observational learning one of the factors that allow for modelling of observed behaviour is that of attentional processes. On the part of the modelled activity factors salience, attractiveness, and functional value are the key attributes (Bandura, 2001, p. 272). In this regard, the theme of attentional processes came up during data analysis, with attractiveness appearing once:

Thus, to Meg, effective messages were those that were carefully crafted, and her scrutiny of discussion threads in preparation for her own reflective messages helped her to gain insight into her own thinking and learning processes. (DeArment, 2002, pp. 143)

Attentional processes include affective valence which includes salience on the part of the modelled activities. This means the modelled activity is viewed as striking and conspicuous. In this regard, this theme appeared in the data analysed, and discussion boards, videos, and learning objects were the media that facilitated this process:

When we can ask questions on the discussion board and see other student work it is helpful. Multimedia classes are more visual and fun online. I think the discussion boards are vital to the class. It's vital to help students succeed and the support from other students is important. (Boster, 2009, pp. 81)

Thomas indicated that the online environment was good for information seeking; retrieval and storage of reading materials, syllabus, or reporting on on-going progress. Barb believes that videos and learning objects are best for the online environment and added, "I think what happens is that if you can make the online environment as visual as possible that really helps the students, that is, if you can move beyond the text. (Ndon, 2006, pp. 108) 
The internet served as a source of modelling events once students realized the functional value of the resources:

The teachers reasoned these gains could be attributed to students accessing research materials on the Internet that were intended for higher grade levels. (Menard, 2010, pp. 56)

\section{Retention processes.}

The retention processes include the active process of transforming and restructuring information conveyed by the modelled events (Bandura,2001, p. 272). One of the ways in which this occurs is through cognitively organising the modelled events. In the data for this research, retention through cognitive modelling occurred and was facilitated by discussion boards:

Repetition of above quoteThe teacher participants discussed how students consistently exceed expectations when using technology. Students are fully engaged by multimedia content that accelerates learning and improves comprehension. The students seem to assimilate digital information easily. (Menard, 2010, pp. 60)

Meg gained insights about her perceptions of effective messages when the researcher asked her to reflect on several of her posts. Meg recognized the value of messages that reflected careful thought and realized that other students' messages could serve as catalysts for her own thought processes. (DeArment, 2002, pp. 142)

In addition, retention processes may occur by symbolic coding in which case the discussion board proved useful in this regard:

Others' posts gave me stuff to kick around and see what came out [when I wrote my thoughts down]. Their posts have helped me to crystallize my ideas, to rethink what I thought I was learning, or to realize that maybe I need to step back and look at this again, or to go to my friends and hash it out with them. (DeArment, 2002, pp. 105)

Bob thought that it was "a different kind of teacher's time" because it is/ was not as fixed as it is in the face-toface class and the discussion forum produced "interesting thought provoking activities." He further stated, "[I] think that the students learn more because 
they are more engaged. I think that they have more opportunities to develop their own approach to logical ideas and to contribute to the work of the class as a whole. (Ndon, 2006, pp. 137)

\section{Production processes.}

The third sub-function of modelling for observational learning is the production process. Bandura (2001, pp. 272) explains that this process involves the translation of symbolic conceptions into appropriate courses of action. Constituent processes associated with the production process include the use of feedback for conception matching. In this regard, quotations related to this theme included:

When the student took Barb's hybrid class, in the faceto-face part, the student again, was noticed to be very quiet. But Barb and other students noticed that in the online environment of the hybrid course, this student was able to express herself very well. She was extremely articulate to a point that some of the students had to wonder who the student was because they were so impressed with her contributions. This example reinforces the notion that going at teaching in two different, but integrated ways improves student's involvement, engagement, and learning. (Ndon, 2006, pp. 140)

A student's individual strengths are recognized and valued. As students present their work to other students, they analyze and evaluate their contribution to the final product. The student "audience" evaluates how individual contributions impact their work as they listen to the presentation. (Menard, 2010, pp. 70)

\section{Motivational process.}

The fourth sub-function in modelling for observational learning as identified by Bandura (2001, pp. 274) is the motivational process which emerged as the most prominent theme in the analysed data. A constituent of this theme includes social incentives. Two quotations associated with social incentives appear below:

In my experience classes were a lot more fun online when you can share views on class work and have discussions as assignments rather then just turning in a weekly assignment. So even if the student is forced to participate and socialize (because it is a required 
assignment) with other online students it was more enjoyable. (Boster, 2009, pp. 69)

The discussion board was a social place to exhibit and discuss multimedia projects and this interaction motivated students to participate and learn online. (Boster, 2009, pp. 102).

A second constituent of motivational processes includes vicarious incentives. Vicarious incentives was inferred once in the data:

EDGE classroom teachers regularly use big concept activities. Incorporating smaller lessons into a large scope project encourages students to work through the fundamentals to get to the "fun part", and steadily expands their research on the project. The finished project is the amalgamation of many different thoughts and ideas created by the student. Student creativity is further enhanced through collaboration and sharing. Technology provides many ways for students to showcase their work. This also helps students who prefer digital solutions to "paper and pencil". (Menard, 2010, pp. 70)

Self-incentives is another constituent of motivational processes and was inferred once:

The imagination that emerges (from online research) is amazing." The teacher continued, "When the story is over in the reading series it's really not over in a technology-based classroom. The students take it so much further than we possibly would have taken it without technology." (Menard, 2010, pp. 64)

External incentives was the constituent of motivational processes in observational learning and was inferred 11 times. The online social medium that served as an external incentive in motivational processes was the discussion board. Some of the quotations related to external incentives are:

Students gained a sense of gratification and motivation when others responded to their posts, and the valued messages that fostered awareness of their peers of individuals and a sense of community. (DeArment, 2002, pp. 134)

[The requirement of submitting to the Discussion Board] motivated me to do some reading before I could respond. 
I feel I have to look at other sources and do active research before it becomes a part of me. I went to the Internet to see some good sites that Ruth had posted on XML. They helped me. (DeArment, 2002, pp. 108)

I'm posting mainly because it's required, but I like to post because it motivates me to read people's posts and I think about how I can apply my knowledge to what they've said. Then I post my own personal applications and examples. For the most part that's how I interact with the Discussion Board. I usually can't learn much from reading; I have to hear everything. I listen in class, and then, if I can, I teach it to someone else. If I can explain it to someone who doesn't understand, I know I will learn it. The Discussion Board lets me do this. (DeArment, 2002, pp. 108)

\section{Discussion of Findings}

The purpose of this meta-ethnographic study was to synthesize previous research theses in order to gain understanding into the experiences of students regarding online media applications, constructivism, and observational learning. This section discusses the emergent themes related to constructivism, observational learning, and the online media that facilitated the learning processes.

In terms of the online media for facilitating constructivist learning, the discussion boards featured as aiding in the elicitation of prior knowledge, which was the first criterion for constructivist learning. Similarly, the discussion boards served as a means of stimulating cognitive dissonance on the part of the students. The discussion boards were used for reflection which is the fourth criterion for constructivist learning. While the discussion board as a reflective tool is consistent with Juwah (2010, pp. 25), the findings of this study suggest the discussion board may serve as a social media online application for stimulating other criteria of constructivist learning. The additional constructivist criteria that the discussion board may facilitate are the elicitation of prior learning and the attainment of cognitive dissonance. The online blog emerged as an additional online social media application that served as a reflective tool on the part of the students. In this regard, the finding is consistent with J uwah (2010, pp. 25). The findings suggest that online blogs stimulate the reflection criterion for constructivist learning. With regard to online social media that stimulate constructivism, the metaethnographic study revealed the discussion board was the most appropriate application. The online blog was useful for facilitating reflection in online learning. 
The meta-ethnographic study was also grounded in observational learning as the theoretical point of departure. The discussion board featured as a means of facilitating attentional processes and retention. In addition, discussion boards were a means through which motivational processes were achieved. The findings suggest in addition to promoting constructivist learning, discussion boards may be used to facilitate attentional, retentional, and motivational processes which are constituents of observational learning amongst students. This is in addition to promoting collaboration, discussion, analysis, synthesis, and evaluation (Clark \& Mayer, 2011, pp. 284-285; Juwah, 2010, pp. 25). Research has shown the benefits of using video in fostering observational learning (Charlop, et al., 2010, pp. 371-393; Charlop-Christy, Le, \& Freeman, 2000, pp. 537-552; Craig, Chi, \& VanLehn, 2009, pp. 779-189; Geiger et al., 2010, pp. 279-383; Keen, Brannigan, \& Cuskelly, 2007, pp. 291-303; LeBlanc, 2010, pp. 333-337; Nikopoulos \& Keenan, 2003, pp. 87-108; Sherer et al., 2001, pp. 140-148;). The findings of this study suggest the use of discussion boards in LMS may be an additional online social media application for facilitating observational learning amongst students.

\section{Conclusion}

This research indicated that discussion boards and online blogs have the potential to contribute to aspects of constructivist and observational learning. Online social media applications are not evident in the area of application of knowledge. As is consistent with application of theory and practical work, students are expected to expand their knowledge beyond the classroom by carrying out experiments and independent investigation (Siemens \& Tittenberger, 2009, pp. 18-19). In this regard, online applications other than social media applications may be utilised. The benefits of online social media applications in LMS are particularly evident as motivational activators.

With the range of applications available to instructors in LMS, choices made for the incorporation of these applications into teaching and learning ought to be made based on the pedagogical possibilities they offer. In this regard, the findings of this study suggest discussion boards form a basis for the facilitation of constructivist and observational learning. As the study only investigated online social media found in LMS, further studies into media that facilitate application of theory and independent investigation ought to be carried out.

As this research used unpublished research theses and dissertations, and the data were sourced from the library repository of the University of South Africa, additional research using published data from alternative repositories may contribute to furthering this research. 


\section{References}

Al-Fadhli, S., \& Khalfan, A. (2009). Developing critical thinking in e-learning environment: Kuwait University as a case study. Assessment \& Evaluation in Higher Education, 34(5), 529-536.

Bandura, A. (1986). Social foundations of thought and action: A social cognitive theory. Englewood Cliffs, NJ : Prentice-Hall.

Bandura, A. (2001). Social cognitive theory of mass communication. Media Psychology, 3(3), 265-299.

Baviskar, S, Hartle, R. T., \&Whitney, T. (2009). Essential criteria to characterize constructivist teaching: Derived from a review of literature and applied to five constructivist-teaching method articles. International J ournal of Science Education, 31(4), 542-550.

Black, E. L., \& Blankenship, B. (2010). Linking students to library resources through the learning management s ystem. J ournal of Library Administration, 50, 458-467.

Boster, M. (2009). Social implications facing online learners: A case study of undergraduate multimedia students (Unpublished doctoral thesis). Walden University, Minnesota.

Charlop, M. H., Dennis, B., Carpenter, M. H., \&Greenberg, A. L. (2010). Teaching socially expressive behaviors to children with autism through video modeling. Education \& Treatment of Children, 33(3), 371-393.

Charlop-Christy, M.H., Le, L., \& Freeman, K. A. (2000). A comparison of video modeling with in vivo modeling for teaching children with autism. J ournal of Autism and Developmental Disorders, 30, 537-552.

Chen, C-H. (2011). Transforming online professional development: The design and implementation of the project-based learning management system (PBLMs) for in-service teachers. British J ournal of Educational Technology, 42(1), E5-E8.

Christie, M., \& Garrote J urado, R. (2009). Barriers to innovation in online pedagogy. European J ournal of Engineering Education, 34(3), 273-279.

Clark, R. C., \& Mayer, R. E. (2008). E-learning and the science of instruction: Proven guidelines for consumers and designers of multimedia learning ( $2^{\text {nd }}$ ed.). San Francisco, CA.: J ossey-Bass. 
Coates, H., J ames, R., \& Baldwin, G. (2005). A critical examination of the effects of learning management systems on university teaching and learning. Tertiary Education and Management, II, 19-36.

Craig, S. D., Chi, M. T. H., \&VanLehn, K. (2009). Improving classroom learning by collaboratively observing human tutoring videos while problem solving. J ournal of Educational Psychology, 101(4), 779-789.

Dalsgaard, C. (2006). Social software: E-learning beyond learning management systems. Retrieved from http:// www.eurodl.org/materials/ contrib/2006/Christian_Dalgaard.htm

DeArment, C. (2002). Instructional uses of computer-mediated text-based messaging tools: a case study of faculty and student experiences and perceptions (Unpublished doctoral thesis).University of Pittsburgh, Pittsburgh.

Geiger, K. B., LeBlanc, L. A., Dillon, C. M., \&Bates, S. L. (2010). An evaluation of preference for video and in vivo modeling. J ournal of Applied Behavior Analysis, 43, 279-383.

Hershey, M. (2010). A social media revolution: What it means for a company's image and the $21^{\text {st }}$ century job search. Retrieved from http:// ww.personal.psu.edu/jmb851/blogs/la_200 -business_and the liberal_arts/Social\%20Media\%20Revolution.pdf

J uwah, C. (2010). The impact of technology on distance education: Implications for developing countries. Institute for Open and Distance Learning $5^{\text {th }}$ lecture in the ODL Occasional lecture series 2010. Pretoria: Institute for Open and Distance Learning, UNISA.

Keen, D., Brannigan, K. L., \& Cuskelly, M. (2007). Toilet training for children with autism: The effects of video modeling category. J ournal of Developmental and Physical Disabilities, 19, 291-303.

LeBlanc, L. A. (2010). Using video-based interventions with individuals with Autism Spectrum Disorders: Introduction to the special issue. Education \& Treatment of Children, 33(3), 333-337.

Liang, J -C., \& Tsai, C-C. (2008). Internet self-efficacy and preferences toward constructivist internet-based learning environments: A study of pre-school teachers in Taiwan. Educational Technology \& Society, 11(1), 226-237.

Loyens, S. M. M., Rikers, R. M. J . P., \& Schmidt H. G. (2007). The impact of students' conceptions of constructivist assumptions on academic achievement and drop-out. Studies in Higher Education, 32(5), 581-602. 
Menard, L. B.. (2010). Elementary teachers' perceptions of technology as a catalyst for constructivist practices in the classroom: A case study (Unpublished doctoral thesis). University of South Florida, Tampa Florida.

Ndon, U. T. (2006). The lived experiences of university faculty who teach using a hybrid instructional model (Unpublished doctoral thesis). University of Wisconsin-Milwaukee, Milwaukee.

Ng’ambi, D., \&Lombe, A. (2012). Using podcasts to facilitate student learning: A constructivist perspective. Educational Technology \& Society, 15(4), 181192.

Nikopoulos, C. K., \& Keenan, M. (2003). Promoting social initiations in children with autism using video modeling. Behavioral Intervention, 18, 87-108.

Noblit, G., \& Hare, R.D. (1988). Meta-ethnography: Synthesizing qualitative studies. In Qualitative research methods (Vol. II). Newbury Park: Sage.

Pritchard, A. (2005). Ways of learning: Learning theories and learning styles in the classroom. Great Britain: David Fulton Publishers.

Sherer, M., Pierce, K. L., Paredes, S., Kisacky, K. L., Ingersoll, B., \& Schreibman, L. (2001). Enhancing conversation skills in children with autism via video technology: Which is better, "self" or "other" as model? Behavior Modification, 25, 140-158.

Siemens, G., \& Tittenberger, P. (2009). Handbook of emerging technologies for learning. Retrieved from http:// elearnspace.org/Articles/HETL.pdf

Stefanone, M. A., Lackaff D., \& Rosen D. (2010). The relationship between traditional mass media and "social media": Reality television as a model for social network site behaviour. J ournal of Broadcasting and Electronic Media, 54(3), 508-525.

Sultan, W.H., Woods, P.C., \&Koo, A-C. (2011). A constructivist approach for digital learning: Malaysian schools case study. Educational Technology \& Society, 14(4), 149-163.

Yang, Y-F, Yeh, H-C, \&Wong, W-K. (2010). The influence of social interaction on meaning construction in a virtual community. British J ournal of Educational Technology, 41(2), 287-306.

Yi, M. Y., \& Davis, F. D. (2003). Developing and validating an observational learning model of computer software training and skill acquisition. Information Systems Research, 14(2), 146-169. 


\section{Athabasca University $\mathbf{I}$}

(c) (†) 